\title{
The Impact of Supplier Orientation on Firm Innovativeness: An Abstract
}

\author{
Abdullah M. Aljafari, Fernando R. Jimenez, and Gary L. Frankwick
}

\begin{abstract}
For over two decades, scholars have investigated the link between market orientation, innovation, and performance. However, the market orientation framework including customer-orientation, competitor-orientation, and cross-functional coordination is outdated. It reflects how vertically-integrated firms innovate. Today, only a handful of firms are vertically integrated. Many firms focus on their core capabilities and outsource to suppliers all other resources. Unfortunately, market orientation overlooks this change. This article fills this void. Drawing from the resource based view of the firm, market orientation is expanded by adding two dimensions: supplier orientation and inter-firm coordination. We postulate that this new model can better explain and predict firm innovativeness and performance in the current global network economy. The moderating role of power, communication richness, and communication frequency are also discussed. The article ends by proposing avenues for future research.
\end{abstract}

References Available Upon Request

\footnotetext{
A.M. Aljafari ( $\square)$

Qatar University, Doha, Qatar

e-mail: abdullah.aljafari@qu.edu.qa2

F.R. Jimenez • G.L. Frankwick

University of Texas at El Paso, El Paso, TX, USA

e-mail: frjimenezarevalo@utep.edu; glfrankwick@utep.edu 